\title{
O lugar da International Association of Labour History Institutions na história dos arquivos e bibliotecas do movimento operário
}

\author{
The Place of the International Association of Labor History \\ Institutions in the History of the Archives and Libraries of the \\ Labor Movement
}

\section{Lucas Poy*}

Resumo: Fundada em 1970, a International Association of Labour History Institutions (IALHI) é uma rede internacional que reúne bibliotecas, arquivos, museus e centros de pesquisa dos cinco continentes. A fundação da IALHI como espaço de articulação e diálogo entre instituições de diversos países (europeus) foi a expressão das inquietações surgidas no campo historiográfico e, mais especificamente, de questões "técnicas" relacionadas com a necessidade de intercambiar informações bibliográficas e de arquivo. O seu alcance inicial foi reduzido, tanto geográfica como ideologicamente, limitando-se a alguns países da Europa Ocidental e a instituições ligadas, sobretudo, ao movimento socialdemocrata. Essa demarcação foi se tornando mais difusa com o passar dos anos e assim acabaram aderindo à associação instituições de diferentes origens geográficas, institucionais e ideológicas. O objetivo deste trabalho é caracterizar a IALHI e as atividades que ela desenvolve no contexto mais geral da história das instituições, arquivos e bibliotecas dedicadas à história do movimento operário e das esquerdas, e de suas relações internacionais.

Palavras-chave: IALHI, história do trabalho, bibliotecas, arquivos, instituições.

* Doutor em História pela Universidad de Buenos Aires. Investigador adjunto do CONICET no Instituto de Historia Argentina y Americana "Dr. Emilio Ravignani". Professor Adjunto na Facultad de Ciencias Sociales de la Universidad de Buenos Aires. Coordenador da International Association of Labour History Institutions (IALHI). E-mail: lucaspoy@gmail.com. ORCID: https://orcid.org/0000-0001-9655-1808.

Este artigo é uma tradução do texto publicado em espanhol na edição 17 da revista Archivos de historia del movimiento obrero y la izquierda. Agradeço a Fabiane Popinigis pelo convite para apresentar o trabalho no seminário organizado pela rede Mundos do Trabalho em 2020 e para publicar uma versão em português na revista. 
Abstract: Established in 1970, the International Association of Labour History Institutions (IALHI) is an international network of libraries, archives, museums, and research centres from five continents. The foundation of the IALHI as a coordination space between institutions from different (European) countries expressed historiographical concerns and, more specifically, 'technical' issues linked to the need to exchange bibliographic and archival information. Its initial scope was reduced, both in geographical and ideological terms, being limited to certain Western European countries and institutions related to the social democratic movement. This demarcation became more blurred over the years, as institutions from different geographical, institutional and ideological backgrounds joined the association. The aim of this paper is to characterise the IALHI and its activities against the background of the history of institutions, archives and libraries dedicated to the history of the labour and its international relations.

Keywords: IALHI, labour history, libraries, archives, institutions

\section{Introdução}

A INTERNATIONAL ASSOCIATION of Labour History Institutions (Associação Internacional de Instituições de História do Trabalho) foi fundada em dezembro de 1970, em Londres, após uma reunião realizada na Transport House, histórica sede política e sindical da capital britânica. A reunião foi pequena e contou com a participação de onze instituições: o Partido Trabalhista, o Trades Union Congress, a London School of Economics e a International Cooperative Alliance (todas com sede em Londres), a Co-operative Union of Manchester, o Instituto Internacional de História Social de Amsterdã, o Working Committee of Co-operative Librarians and Documentation (Rotterdam), o Schweizerisches Sozialarchiv (Zurique), o Abteilung Werbung-Archiv, Deutscher Gewerkschaftsbund (Düsseldorf), a Friedrich-Ebert-Stiftung (Bonn) e o Arbetarrörelsens arkiv (Estocolmo)

Passados cinquenta anos, a IALHI continua ativa e cresceu até se tornar uma rede que reúne bibliotecas, arquivos, museus e centros de pesquisa dos cinco continentes. Atualmente conta com mais de 120 membros: de instituições universitárias a fundações sindicais, centros de pesquisa vinculados a partidos políticos e museus populares, passando por grupos de estudos de diversos portes, arquivos e bibliotecas públicas e privadas. Apesar das suas heterogeneidades, todas compartilham a preocupação pela conservação de materiais e documentação sobre a história dos trabalhadores e das trabalhadoras, do movimento operário e dos partidos políticos proletários.

A $52^{\mathrm{a}}$ conferência anual da IALHI, referente ao ano de 2022, será realizada em Buenos Aires e é organizada pelo Centro de Estudios Históricos de los Trabajadores y las Izquierdas (CEHTI), integrante oficial da associação desde 2018. Será a primeira vez que o evento vai ser realizado na América Latina e apenas a quarta vez, em cinquenta anos, que será 
realizado fora da Europa (em 1997 e 2014 foi realizado nos Estados Unidos e em 2008 na África do Sul). Trata-se, portanto, de um momento importante para a IALHI e ainda mais para o CEHTI, uma associação jovem que vai assumir essa responsabilidade com o intuito de continuar tecendo redes, construindo pontes e espaços de diálogo coletivo com colegas e outras associações de todo o mundo e, em particular, da Argentina e da América Latina. Como primeiro passo na preparação da conferência, o objetivo desta comunicação é proporcionar uma breve apresentação da IALHI e das atividades que realiza no contexto mais geral da história das instituições, arquivos e bibliotecas dedicadas à história do movimento operário e das esquerdas e das suas relações internacionais.

\section{Arquivos, bibliotecas e centros sobre a história operária: um breve percurso histórico}

EMBORA A PREOCUPAÇÃo em examinar as tradições populares possa ser encontrada ao longo do século XIX, ${ }^{1}$ os primeiros passos tanto de uma história do movimento operário quanto de uma história do trabalho e suas condições (campos de análise que, em inglês, costumam combinar-se na expressão 'labour history'), ocorreram nas últimas décadas daquele século. Obviamente, os avanços estiveram relacionados ao desenvolvimento das organizações operárias, mas também à preocupação de reformistas de classe média, acadêmicos e até religiosos, que se preocuparam com a "questão social" e com o conflito que ela trazia, e consideraram importante reunir informação e material sobre o assunto.

Assim como aconteceu em muitas outras áreas, o partido socialdemocrata alemão (SPD) foi o pioneiro na iniciativa de criar um arquivo partidário. Devido às leis de emergência, primeiro foi fundado em Zurique, depois levado para Londres e finalmente para Berlim, no início da década de 1890. Foi aberto ao público em 1899, embora fosse necessária uma licença das autoridades partidárias para consultá-lo. O arquivo continha, entre outras coisas, as bibliotecas privadas de Marx e Engels. ${ }^{2} \mathrm{O}$ exemplo alemão foi seguido de perto pela crescente socialdemocracia escandinava, que logo tomou medidas semelhantes. Arquivos e bibliotecas foram criados na Suécia, Noruega, Dinamarca e Finlândia na primeira década do século 20 e hoje ainda existem: Arbetarrörelsens Arkiv och Bibliotek, em Estocolmo (1902), Arbeiderbevegelsens Arkiv og Bibliotek, em Oslo (1908), Arbejdermuseet \& Arbejderbevægelsens Bibliotek og Arkiv, em Copenhague (1909) e Työväen Arkisto em Helsinki (1909). ${ }^{3}$

1 KLOOSTERMAN, Jaap. Unwritten autobiography: labor history libraries before world war I. In: VAN DER LINDEN, Marcel; LUCASSEN, Leo (ed.). Working on Labor: Essays in Honour of Jan Lucassen. Leiden: Brill, 2012. p. $395-416$

2 ZIMMERMANN, Rüdiger. Das gedruckte Gedächtnis der Arbeiterbewegung bewahren: Die Geschichte der Bibliotheken der deutschen Sozialdemokratie. Bonn: Veröffentlichungen der Bibliothek der Friedrich-EbertStiftung, 2008.

3 KLOOSTERMAN, op. cit., p. 413. HALVORSEN, Solveig. The Norwegian Labour Movement Archives and Library. Saothar, n. 20, p. 105-107, 1995. GRASS, Martin; LARSSON, Hans. Labour's Memory: The Labour Movement Archives and Library 1902-2002. Estocolmo: Arbetarrörelsens arkiv och bibliotek, 2002. 
Por sua vez, vários reformadores e liberais ou religiosos preocupados com a "questão social" também fizeram avanços significativos nesses anos. Em 1894 foi criado em Paris o Musée Social, instituição que, entre o final do século XIX e começo do século XX, teve uma grande influência na vida política e intelectual francesa e que tinha como um dos seus objetivos fundacionais "a melhoria da situação moral e material dos trabalhadores". ${ }^{4} \mathrm{O}$ exemplo do Musée Social, como é sabido, deixou sua marca em muitos países, inclusive na Argentina. ${ }^{5}$ Seguindo o modelo francês, o pastor e político suíço Paul Pflüger fundou o Schweizerische Sozialarchiv em Zurique em 1906. Na Inglaterra, o Bishopsgate Institute foi fundado em 1894 , por iniciativa de um reverendo chamado William Rogers. ${ }^{6}$ Um ano depois, a Fabian Society promoveu a criação da London School of Economics, com Sydney e Beatrice Webb e George Bernard Shaw em destaque. ${ }^{7}$ Nos Países Baixos, o Centraal Bureau voor Sociale Adviezen foi criado em 1899. ${ }^{8}$ Podemos também incluir nesse grupo a Biblioteca Pública Arús, fundada em Barcelona, em 1895, a partir das doações do republicano liberal Rossend Arús, que após sua morte, em 1891, instruiu seus herdeiros a usarem seus bens para criar uma biblioteca que contribuiria para a educação dos trabalhadores. ${ }^{9}$ Nos Estados Unidos, foi estabelecida nestes anos outra das instituições mais representativas, de alguma forma produto de um cruzamento entre iniciativas socialistas e filantrópicas. De fato, em 1906, a Rand School of Social Science foi fundada em Nova York, como consequência das doações fornecidas por Carrie Rand, por iniciativa de seu enteado George D. Herron, membro do Partido Socialista. A instituição foi posteriormente absorvida pelo Camp Tamiment, uma colônia de verão para socialistas no lago de mesmo nome na Pensilvânia, e ficou conhecida como Tamiment Library. Em 1963, passou a fazer parte da New York University, à qual ainda hoje é filiada. ${ }^{10}$

Nestes anos, também vale destacar a fundação da revista Archiv für die Geschichte des Sozialismus und der Arbeiterbewegung, em 1911, por iniciativa do marxista austríaco Carl Grünberg (1861-1940), que na década de 1920 se tornaria diretor da Escola de Frankfurt.11 Um pouco mais tarde, e como consequência da Primeira Guerra Mundial, surgiram outras instituições importantes. Henri e Louise Leblanc começaram a coletar materiais ligados ao conflito, formando uma Bibliothèque-Musée da Guerre, que mais tarde se tornaria a renomada Bibliothèque de Documentation Internationale Contemporaine (BDIC), associada

4 HORNE, Janet (1995). Le Musée social à l'origine: les métamorphoses d'une idée. Le Mouvement social, n. 171 , p. 47.

5 PELOSI, Hebe. EI Museo Social Argentino y la Universidad del Museo Social Argentino: historia y proyección (1911-1978). Buenos Aires: Universidad del Museo Social, 2000.

6 SAMUEL, Raphael. The Bishopsgate Institute. History Workshop, n. 5, p. 163-172, 1978.

7 CAINE, Sydney. The History of the Foundation of the London School of Economics and Political Science. Londres: London School of Economics, 1963. DAHRENDORF, Ralf. LSE: A History of the London School of Economics and Political Science 1895-1995. Oxford: Oxford University Press, 1995

8 KLOOSTERMAN, Jaap; LUCASSEN, Jan. Rebels with a cause: five centuries of social history collected by the International Institute of Social History. Amsterdã: Aksant, 2010. p. 11.

9 KLOOSTERMAN, op.cit., p. 409. GALOFRÉ, Jordi. Rossend Arús i Arderiu (1845-1891). Barcelona: Ajuntament de Barcelona, 1989.

10 BELL, Daniel. The Tamiment Library. Nova York: New York University Libraries, 1969.

11 WIGGERSHAUS, Rolf. La Escuela de Fráncfort. México: Fondo de Cultura Económica, 2010. 
à Universidade de Nanterre. ${ }^{12}$ Outro exemplo semelhante é a Hoover Institution on War, Revolution and Peace, baseada nos materiais reunidos por Herbert Hoover em seus anos como enviado à Europa durante a guerra. Hoover foi, anos depois, presidente dos Estados Unidos, e a Hoover Institution foi posteriormente integrada à Universidade de Stanford. No outro extremo do espectro político, como consequência da revolução russa e, em particular, da obra de David Riazanov, o Instituto Marx-Engels abriu suas portas em Moscou em 1921. Seu principal objetivo era reunir materiais e fontes relacionadas com a obra dos dois fundadores do socialismo científico, assim como publicar suas obras. A história do instituto e do seu fundador, logicamente, é inseparável da trajetória seguida pela União Soviética em seu processo de burocratização: Riazanov foi preso em 1931 e executado em 1938. O Instituto Marx-Engels foi fundido com o Instituto Lenin, que tinha sido criado em 1924, dando origem ao Instituto Marx-Engels-Lenin.

Outra instituição que surgiu no período entre guerras e continua desempenhando um papel muito importante na IALHI e na história dos trabalhadores em todo o mundo é o Internationaal Instituut voor Sociale Geschiedenis (Instituto Internacional de História Social) em Amsterdã. A sua história está intimamente ligada à figura de Nicolaas Willem Posthumus, historiador e arquivista ligado à socialdemocracia holandesa. Em 1914, Posthumus tinha fundado o NEHA, um arquivo de história econômica, ligado ao já citado Centraal Bureau voor Sociale Adviezen e a diversos sindicatos. Na década de 1930, o projeto Posthumus deu um salto muito importante, quando percebeu a necessidade e a oportunidade de reunir materiais de vários países europeus que corriam sérios riscos diante do avanço do fascismo. Foi fundamental o papel de Annie Scheltema, bibliotecária e arquivista do Partido Socialdemocrata holandês, assim como o do menchevique russo Boris Nicolaevski, então exilado em Paris. Essa ampliação da escala das coleções estava fora da capacidade financeira da NEHA, e Posthumus obteve apoio econômico de uma seguradora ligada aos sindicatos e à socialdemocracia. Graças a essa contribuição, o IISG foi inaugurado em novembro de 1935, em um prédio doado pela prefeitura de Amsterdã. ${ }^{13}$

O fato de todas as instituições mencionadas até agora estarem localizadas em países europeus ou nos Estados Unidos é revelador do início da consolidação das organizações políticas e sindicais do movimento operário nessas regiões, mas também, e talvez fundamentalmente, dos seus maiores recursos financeiros e técnicos e, em relação a isso e com os laços coloniais de seus próprios estados, de sua capacidade de até mesmo coletar

12 HUE, Joseph (ed.). BDIC 1917-2000: Bibliothèque de Documentation internationale contemporaine: un organisme public d'information et de recherche international. Nanterre: BDIC, 1997.

13 Em 1936, ele começou a publicar um anuário, chamado International Review for Social History. Depois da guerra, retomou sua publicação com o nome de International Review of Social History, que mantém atualmente. Sobre a história do IISG, ver HUNINK, Maria. De papieren van de revolutie: het Internationaal Instituut voor Sociale Geschiedenis, 1935-1947. Amsterdã: IISG, 1986. ROTH, Karl Heinz. The International Institute of Social History as a Pawn of Nazi Social Research. New documents on the IISH during German Occupation Rule from 1940 to 1944. International Review of Social History, v. 34, Supplement p. 1-88, 1989. KLOOSTERMAN; LUCASSEN, op. cit. SANDERS, Huub. Het virus der betrokkenheid. Het Internationaal Instituut voor Sociale Geschiedenis 1935-1989. Amsterdã: Amsterdam University Press, 2019. 
documentação, arquivos e material bibliográfico de países mais pobres. De fato, a relativa fragilidade dos partidos e sindicatos, o desinteresse das instituições estatais e acadêmicas pela questão operária, a perseguição e a repressão estatal foram fatores que se combinaram e dificultaram seriamente a estruturação das instituições e arquivos da história operária nos países periféricos, em muitos casos deixando a tarefa de conservação e coleta nas mãos de colecionadores privados. Assim como Horacio Tarcus apontou em um exame do caso argentino, esses mesmos colecionadores, muitas vezes, acabavam vendendo ou doando seus acervos a instituições de países ricos, aprofundando dessa forma o processo mencionado, ou a diferentes livreiros e compradores privados, desmantelando as coleções. ${ }^{14}$

Nas décadas posteriores à Segunda Guerra Mundial, houve um novo processo de expansão das instituições dedicadas à história do trabalho em diversos países da Europa Ocidental, fenômeno vinculado ao crescente interesse pela história social e operária em certas esferas intelectuais e universitárias, à consolidação de partidos socialdemocratas já fortemente integrados aos regimes políticos de muitos desses países, e também ao crescimento dos partidos comunistas. Em 1949, e sob o impulso de Jean Maitron, foi estabelecido na França o Institut Francais d'Histoire Sociale. Como parte de suas atividades, o IFHS começou a publicar Actualité de l'histoire (1953-1960), que mais tarde foi renomeado Le mouvement social (1960). ${ }^{15} \mathrm{Na}$ Itália, da segunda pós-guerra, surgiram uma infinidade de instituições e fundações dedicadas à história do movimento operário e do pensamento de esquerda, muitas das quais continuam existindo ainda hoje: a Itália é de fato o país mais representado na IALHI, com 17 instituições, quase $15 \%$ do total. Entre as mais importantes, vale citar duas, fundadas no início da década de 1950 e intimamente ligadas ao Partido Comunista Italiano: o Istituto Gramsci de Roma, fundado em 1950, e a Biblioteca Giangiacomo Feltrinelli (mais tarde denominada Istituto e agora Fondazione) fincada um ano depois, em Milão. Entre outras coisas, ambas as instituições lançaram publicações altamente reconhecidas: em 1959, o IG começou a publicar Studi Storici, que continua até hoje; Feltrinelli, por sua vez, lançou primeiro uma publicação chamada Movimento Operaio e, a partir de 1958, seus conhecidos Annali. ${ }^{16}$

Avanços semelhantes ocorreram em outros países europeus: em 1959, foi criado em Viena o Verein für Geschichte der Arbeiterbewegung e no ano seguinte surgiu na Grã-Bretanha a Society for the Study of Labour History. ${ }^{17}$ Em 1969, uma socialdemocracia reconstruída criou

14 TARCUS, Horacio. Los archivos del movimiento obrero, los movimientos sociales y las izquierdas en la Argentina: Un caso de subdesarrollo cultural. Políticas de la Memoria, n. 10/11/12, p. 7-18, 2011.

15 CEAMANOS-LLORENS, Roberto. La internacionalización de la historia obrera y social francesa. Studia Historica. Historia Contemporánea, n. 22, p. 301-317, 2004. CEAMANOS-LLORENS, Roberto. La historia obrera y social contemporánea a través del estudio de Le Mouvement Social (1960-2000). Anuario Colombiano de Historia Social y de la Cultura, n. 33, p. 311-336, 2006.

16 GORI, Francesca. La Fondazione Giangiacomo Feltrinelli à Milan. Matériaux pour l'histoire de notre temps, n. 10, p. 19-21, 1987. BIDUSSA, Davide. La Biblioteca Feltrinelli dall'Accumulazione originaria' alla nascita degli 'Annali' (1950-1959). Studi Storici, v. 40, n. 4, p. 945-991, 1999.

17 VAN DER LINDEN, Marcel. The Growth of a European Network of Labor Historians. International Labor and Working-Class History, n. 90, p. 266-273, 2016, p. 267. MCILLROY, John et al. Making History: Organizations of Labour Historians in Britain since 1960. Leeds: Maney Publishing, 2010. 
o Archiv der Operario Demokratie, em Bonn, capital da Alemanha Ocidental nesse período. ${ }^{18}$ Nesse contexto de relativa expansão da história social e do trabalho em vários países europeus, surgiu também, embora de forma lenta, a preocupação por estabelecer alguns diálogos internacionais. Em 1964, por exemplo, foi fundada na Áustria a ITH (International Conference of Labour and Social History), uma rede que ainda hoje está ativa e que reúne instituições e pesquisadores, organizando as conhecidas "conferências de Linz". ${ }^{19}$

\section{A IALHI e sua composição: entre a Guerra Fria e a abertura ao "Sul global"}

ACRIAÇÃo da IALHI deu-se nesse contexto europeu marcado pela consolidação de instituições dedicadas à história do trabalho, mas também num período marcado pelo surgimento dos movimentos estudantis e populares e pelo auge da Guerra Fria. A iniciativa que levou à reunião de fundação partiu de Irene Wagner, bibliotecária do Partido Trabalhista britânico, instituição que desempenhou um papel muito ativo nos primeiros anos da associação, mas que posteriormente foi declinando. Em maio de 1970, Wagner havia enviado uma carta a colegas de outros países, para trocar ideias sobre possíveis formas de colaborar e "formar uma associação de bibliotecários que compartilham as mesmas ideias". ${ }^{20}$

Como Huub Sanders apontou em um trabalho recente, as instituições que participaram do evento de fundação representavam "uma combinação de instituições do movimento (...) e instituições especializadas que reuniam materiais e faziam pesquisas sobre o movimento". ${ }^{21} \mathrm{~A}$ maior parte dos centros e institutos reunidos em Londres, em 1970, já tinham várias décadas de existência e era inegável o peso das instituições ligadas de uma forma ou de outra à socialdemocracia, bem como o enfoque geográfico nos países do norte da Europa. Entre os fundadores, havia apenas instituições de cinco países: Grã-Bretanha, Países Baixos, Suécia, Suíça e Alemanha Ocidental.

Embora a associação tenha sido fundada com objetivos estritamente acadêmicos e técnicos, sem incluir qualquer referência explícita de natureza política, a verdade é que a questão das afinidades ideológicas dos membros potenciais e, portanto, da IALHI como tal, nunca foi escondida. Embora tenha sido mencionado que os novos membros poderiam vir "tanto do oeste quanto do leste", a cautela era evidente nas atas da reunião de fundação: foi

18 ZIMMERMANN, Rüdiger. From Ice Age to Global Warming. The Libraries of the Amsterdam IISH and the FriedrichEbert-Stiftung (FES). In: BLOK, Aad; LUCASSEN, Jan; SANDERS, Huub (ed.). A Usable Collection. Essays in Honour of Jaap Kloosterman on Collecting Social History. Amsterdã: Amsterdam University Press, 2014.

19 Mesmo nos anos após a criação da IALHI, novas e importantes instituições foram fundadas, como a Irish Labour History Society (1973), o Arquivo Edgard Leuenroth de São Paulo (1974) e o Instituto de História Social - Amsab, em Gante, Bélgica (1980). Na última década também se estabeleceram algumas redes como a Società italiana di storia del lavoro (2012), a Association française pour l'histoire des mondes du travail (2013) e a European Labour History Network (2015).

20 SCHUSTER, Dieter. Chronik und Dokumente zur frühen Geschichte der International Association of Labour History Institutions (IALHI). Bonn: Friedrich Ebert Stiftung, 2008. p. 3.

21 SANDERS, op. cit., p. 336. 
apontado que "no que diz respeito às instituições não europeias, elas poderiam ser aceitas em uma data posterior". ${ }^{22} \mathrm{Na}$ mesma linha, a segunda conferência, realizada em Estocolmo no verão de 1971, enfatizou que "os que pertencem a organizações socialdemocratas com bibliotecas e arquivos têm um papel especial a desempenhar". As atas dessa conferência não escondiam o fato de que "certas preocupações foram expressas sobre a conveniência de incluir certos setores do movimento operário", e foi decidido que "a secretaria deveria entrar em contato com a Internacional Socialista com vistas as suas sugestões para adesão". ${ }^{23}$

Em particular, o principal ponto em jogo era a relação com as instituições ligadas ao bloco soviético e aos partidos comunistas da Europa Ocidental, um ponto delicado para as bibliotecas e arquivos dos trabalhadores, pois às vezes se viam "competindo" entre si pelos materiais de arquivo. ${ }^{24} \mathrm{~A}$ tensão atingiu o clímax alguns anos depois, quando a IALHI discutiu uma iniciativa mexicano-russa para criar uma nova organização mundial de instituições e pesquisas sobre a história do trabalho. As atas do $8^{\circ}$ congresso (Viena, 1977) informavam sobre "as manobras de várias organizações do Leste Europeu nesta primavera, que causaram uma comoção considerável entre os nossos membros". ${ }^{25}$ Foram realizadas reuniões, tendo Milan e Feltrinelli como uma espécie de campo neutro, para discutir as possibilidades e limites da cooperação entre a IALHI e a nova organização. Coletivamente, os membros da IALHI se esforçaram para preservar sua "integridade" e evitar serem absorvidos para uma nova associação. No final, não foi criada nenhuma outra organização global permanente e as tensões se dissiparam. ${ }^{26}$

De qualquer forma, a IALHI cresceu de forma constante nas primeiras duas décadas de sua existência, passando de 15 membros em 1972 para 38 em 1974, 48 em 1977, 69 em 1980 e 93 em 1988. A queda do muro de Berlim e dos regimes do chamado "socialismo real" diluíram significativamente o caráter europeu-ocidental da IALHI, bem como sua orientação ligada à socialdemocracia: não apenas as instituições do antigo bloco soviético foram incorporadas, mas passou-se a considerar a necessidade de aumentar a presença de centros de outros continentes. Em 1995, a conferência anual foi realizada em Moscou: foi um sintoma dos novos tempos.

Na década de 1990, começou a surgir a preocupação de estender geograficamente a atividade da IALHI e incluir membros de outras regiões. Em 1992, por iniciativa da Fundação Pablo Iglesias, da Espanha, foi realizada uma reunião em Buenos Aires que contou com a presença de instituições de mais de uma dezena de países ibero-americanos. O resultado foi a criação de uma "Asociación iberoamericana para la recuperación y protección de los archivos de los trabajadores y sus organizaciones" (AIRPATO), que infelizmente não conseguiu se

22 SCHUSTER, op. cit., p. 9.

23 Ibidem, p. 11.

24 Para uma análise dessa complexa dinâmica de tensões e colaborações no caso do IISG e da Fondazione Feltrinelli, veja o excelente trabalho de KLOOSTERMAN, op. cit., 2014.

25 SCHUSTER, op. cit., p. 17.

26 KLOOSTERMAN, Jaap. In Bebels voetspoor: Wouter Steenhaut en de IALHI. Brood \& Rozen Special, p. 2735,2009 
sustentar com o tempo. ${ }^{27} \mathrm{Em} \mathrm{1997,} \mathrm{pela} \mathrm{primeira} \mathrm{vez} \mathrm{em} 27$ anos, a reunião anual da IALHI foi realizada fora da Europa, no George Meany Center for Labor Studies, localizado perto de Washington D.C., nos Estados Unidos. Em 2008, foi realizada em Johanesburgo, na África do Sul. Atualmente, a IALHI conta com 121 membros provenientes dos cinco continentes. Com 94 instituições (77\%), a Europa ainda representa uma esmagadora maioria, mas a proporção de membros de outras regiões está crescendo: são 10 instituições da América Latina (Argentina, Brasil, Bolívia, Cuba e México), 8 dos Estados Unidos e Canadá, 5 da Ásia (Japão, Nepal, Vietnã e Indonésia), 3 da Austrália e 1 da África do Sul. ${ }^{28}$

\section{Estrutura e organização}

OS FUNDADORES da IALHI dotaram-na de uma estrutura simples, que posteriormente foi modificada em alguns aspectos, mas não foi alterada na sua essência. O eixo central da organização foi, e continua sendo, a realização de um evento anual, que serviria de ponto de encontro para trocar experiências, conhecimento e informação. Este papel fundamental atribuído ao encontro anual reduziu a importância de estabelecer organismos mais permanentes e, ao mesmo tempo, contribuiu para aprofundar a limitada expansão geográfica da rede, visto que realizar esse tipo de viagens anuais é muito mais difícil se aumenta a distância a ser percorrida pelos participantes.

A primeira reunião, de qualquer forma, nomeou a própria Irene Wagner como secretária. Wagner permaneceu nessa posição ao longo da década de 1970 e, em 1980, foi substituída por Karl Lang, do Schweizerisches Sozialarchiv de Zurique. Em 1987, Jaap Kloosterman, do IISG de Amsterdã, assumiu e atuou como secretário até 1996. Desde então, os secretários cumpriram "mandatos" de no máximo cinco anos, e o cargo continuou sendo rotativo entre as diferentes instituições que sempre estiveram mais ativas na associação: entre 1996 e 2002, o secretário foi Wouter Steenhaut, do Instituto de História Social de Gante (Amsab), depois foi a vez de Karin Englund do ArAB de Estocolmo (2002-2005), Françoise Blum do Centre d'Histoire Sociale du XXème Siècle (entre 2005 e 2010), Erik-Jan Zürcher do IISG (20102012) e Geert Van Goethem, também da Amsab (2013-2018). Atualmente, a presidenta (o novo nome da secretária após uma alteração estatutária) é Anja Kruke, do Archiv der sozialen Demokratie da Fundação Friedrich Ebert, de Bonn.

$\overline{27}$ As comunicações apresentadas na conferência foram publicadas em MARTíN NÁJERA, Aurelio; GARRIGÓS, Agustín. Documentos de la Primera Reunión Iberoamericana para la Recuperación y Conservación de Archivos y Documentación de los Trabajadores y los Movimientos Sociales: Buenos Aires, 13-15 abril 1992. Madrid: Editorial Pablo Iglesias, 1992. O volume fornece informação muito valiosa - embora obviamente desatualizada - sobre a situação dos arquivos e bibliotecas dos trabalhadores na América Latina e pode ser complementado com outra importante compilação sobre as instituições de história operária no Brasil (MARQUES, Antonio; STAMPA, Inez (ed.). O mundo dos trabalhadores e seus arquivos. Rio de JaneiroSão Paulo: Arquivo Nacional/Central Única dos Trabalhadores, 2010). Sem dúvida, as conquistas e limites da experiência da AIRPATO serão objeto de debate na conferência da IALHI em 2022 e ponto de partida para novos avanços.

28 Ver a lista atual de membros em: http://www.ialhi.org/members. 
A estrutura organizacional tornou-se um pouco mais complexa com o passar dos anos e com o crescimento da associação. Na primeira reunião, ficou estabelecido que os institutos de Amsterdã e Estocolmo colaborariam com as "tarefas administrativas" requeridas pela nova organização. Também era geralmente assumido que a instituição à qual pertencia o responsável provisório da secretaria contribuía com diversas tarefas práticas, como a cobrança de anuidades e também se encarregaria da correspondência. A preparação da conferência anual ficava por conta da instituição organizadora. Em 1985, em todo o caso, deu-se mais um passo com a criação de uma "comissão coordenadora" com cinco membros, cuja função era apoiar a atividade da secretaria. Em 2005, foi decidido que as tarefas administrativas continuariam a cargo do IISG em caráter permanente, ao invés de rotatividade produto da mudança do responsável pela secretaria/presidência. Em 2011, também foi criada uma fundação, com estrutura jurídica e com sede nos Países Baixos, para facilitar os procedimentos administrativos.

Em termos financeiros, a IALHI sustentou-se desde sua origem produto de uma contribuição anual realizada por parte das instituições que a integram. Uma vez que as despesas permanentes são muito baixas, a anuidade foi sempre mantida em níveis bastante baixos e os fundos arrecadados são usados principalmente para organizar a conferência anual. Porém, desde pelo menos a década de 1980, também tem buscado, embora nem sempre com sucesso, obter financiamentos especiais para a realização de projetos específicos.

\section{Projetos e iniciativas}

A IALHI não foi fundada por acadêmicos ou pesquisadores, mas principalmente por bibliotecários e arquivistas: a necessidade de estabelecer contatos mais próximos foi, sem dúvida, devido ao crescimento do interesse pela história do trabalho e, portanto, à preocupação por olhares mais internacionais, mas o interesse fundamental permaneceu técnico. Segundo Jaap Kloosterman, a necessidade de uma cooperação mais estreita entre as instituições dedicadas à história do trabalho "foi motivada, entre outras coisas, pelo forte aumento das publicações sobre o assunto: ficou mais difícil saber o que estava aparecendo sobre o assunto, mais difícil comprar tudo e mais interessante o intercâmbio". ${ }^{29}$ Irene Wagner explicou que a conferência anual da IALHI se tornaria "o fórum para a troca não só de material, mas também para a discussão de problemas técnicos". O conhecimento mútuo foi fundamental: "um aspecto muito importante da conferência é o contato pessoal não só com os membros da associação, mas também com as pessoas dos vários institutos que participam da conferência como convidados. A informação através das fronteiras nacionais fica mais fácil quando você conhece, cara a cara, a pessoa com quem está lidando" ${ }^{30}$

29 KLOOSTERMAN, op. cit., 2009.

30 WAGNER, Irene. Report on the International Association of Labour History Institutions. International Labor and Working-Class History, n. 13, 1978, p. 18. 
Tratava-se de um período em que não apenas as fontes documentais e os livros conservados pelas diferentes instituições estavam, na sua totalidade, em formato físico: o mesmo acontecia com os diretórios, catálogos e listas que reuniam informações sobre esses materiais. Como já foi dito, de fato, um dos principais motivos que levaram à fundação da IALHI foi a necessidade de partilhar esse tipo de informação entre diferentes instituições dedicadas ao mesmo tema. Ou seja, era necessário saber quais os livros, arquivos e documentos que cada instituição tinha, para posteriormente solicitar um empréstimo interbibliotecas, uma doação (no caso de materiais duplicados) ou pelo menos sugerir aos pesquisadores interessados que se desloquem à cidade onde eles poderiam encontrar os materiais. Era comum, na época, fazer longas listas de fontes e materiais, que podiam ser compartilhadas e trocadas em diferentes instituições.

Os objetivos da nova instituição, conforme aprovado na conferência de fundação, eram: "fomentar uma cooperação mais estreita entre as instituições da associação, fazer empréstimos interbibliotecas, sempre que possível, publicar bibliografias, listas etc., trocar publicações e materiais duplicados". ${ }^{31}$ Nas primeiras reuniões, também foi discutida a possibilidade de empreender projetos maiores, mas prevaleceu uma atitude cautelosa. Na segunda conferência, realizada em Estocolmo, em agosto de 1971, após uma “longa discussão", houve "a sensação geral de que não era realista apontar muito alto e que as questões práticas, importantes para nós, deveriam ser na forma de pequenos projetos, gerenciáveis, que não acabassem consumindo muito tempo e trabalho". ${ }^{32}$ Algumas dessas iniciativas adicionais foram: a publicação de um Newsletter mensal com informação sobre atividades e notícias; trabalhos de compilação de fontes; e a edição de um diretório com informações sobre as diferentes instituições.

Como é evidente, as transformações técnicas propiciadas pelo desenvolvimento da informática, em primeiro lugar, e especialmente da internet, um pouco mais tarde, marcaram significativamente o desenvolvimento da associação. Apesar do claro predomínio dos materiais físicos, desde a década de 1970 iniciaram-se discussões sobre as possibilidades que o uso de computadores poderia aportar. Isso incluía, por um lado, debates e intercâmbios nas conferências sobre as possibilidades técnicas que as próprias instituições foram descobrindo em termos de catalogação dos materiais e, posteriormente, também da sua digitalização e divulgação. Por outro lado, também levantou a possibilidade de empreender iniciativas comuns, como a IALHI, que fossem além da troca de publicações e catálogos em papel.

Um exemplo desse tipo de inquietude foi o lançamento, a partir de 1997, do Labour History Serials Service, serviço que consistia na compilação de índices de revistas acadêmicas especializadas no assunto. Embora não incluísse o conteúdo dos artigos, o simples fato de listar os títulos de cada um dos artigos contidos em cada número já constituía um avanço

31 SCHUSTER, op. cit., p. 9.

32 Ibidem, p. 11. 
significativo, pois do contrário os catálogos registrariam apenas o título da revista que cada instituição possuía entre suas coleções, sem que fosse possível conhecer os títulos e autores dos textos publicados. O serviço recolheu quase 4 mil exemplares de um total de 128 revistas: deixou de funcionar em 2013, quando a disponibilização das mesmas informações na internet o tornou obsoleto. ${ }^{33}$

Outro exemplo, em 2000, foi a substituição da Newsletter da IALHI, publicado mensalmente em formato impresso e posteriormente enviado também por e-mail, por um serviço de notícias publicado diretamente na web, antecedente do que atualmente é o Social History Portal News Service, um portal de anúncios de atividades acadêmicas, publicações, acervos e eventos relacionados à história do trabalho, que é atualizado on-line, distribuído mensalmente por e-mail e que também possui canais de distribuição nas redes sociais. ${ }^{34}$

Ainda em 2000, iniciou-se um projeto mais ambicioso, que pretendia criar uma plataforma on-line capaz de recolher informação sobre os acervos de arquivo e acervos bibliográficos das diferentes instituições. O objetivo era tornar mais acessíveis os catálogos de cada uma das instituições. Seguiu-se uma iniciativa mais ampla, denominada HOPE Project, que decorreu entre 2010 e 2013 e, finalmente, com financiamento especial da União Europeia, resultou num motor de pesquisa centralizado denominado Social History Portal. Atualmente, - SHP funciona como um portal comum de acesso a uma série de coleções de arquivos, bibliotecas e centros de documentação, onde os usuários podem pesquisar e navegar por mais de 140 coleções, compreendendo mais de 2 milhões de registros, incluindo 900.000 objetos digitalizados (arquivos, livros, brochuras, fotografias, cartazes, gravuras, desenhos animados, som, filmes e vídeos). Atualmente, as coleções disponíveis no SHP correspondem a 21 arquivos e bibliotecas de 13 países europeus. ${ }^{35}$

\section{Conclusão}

AO LONGO de mais de um século e meio, a historiografia do movimento operário, da classe trabalhadora e das esquerdas atravessou etapas muito diversas, com evidentes disparidades regionais, temáticas e metodológicas. Como já foi apontado em numerosas ocasiões, este foi um campo no qual predominavam enfoques centrados nos diferentes países: trata-se, logicamente, de uma delimitação que não pode ser atribuída exclusivamente (e nem sequer principalmente) aos historiadores e historiadoras, já que os próprios partidos políticos, sindicatos e organizações operárias tendiam a se estruturar em escala nacional.

Essa tendência se expressou não apenas em termos de produção historiográfica (tanto acadêmica como "militante", e toda a imensidão de cinzas intermediários), mas também, como vimos, ao nível das instituições dedicadas à coleta de fontes documentais e materiais

33 https://socialhistoryportal.org/serials.

$34 \mathrm{https}: / /$ socialhistoryportal.org/news.

35 http://shp2.amsab.be/. 
bibliográficos: a grande maioria eram instituições e centros "nacionais", vinculados, em muitos casos, a partidos e sindicatos de um determinado país. Ao mesmo tempo, o peso das tradições ideológicas e, logicamente, o próprio caráter internacional da classe trabalhadora e suas lutas, nunca deixou de estar presente e promoveu, em vários momentos, a preocupação em desenvolver enfoques comparativos e olhares mais globais.

A fundação da IALHI como espaço de articulação e diálogo entre instituições de diversos países (europeus) foi a expressão das inquietações que surgiram no campo historiográfico (tal como foi a fundação do ITH e de outros espaços transnacionais, que posteriormente se desenvolveriam) e, mais especificamente, de questões "técnicas" relacionadas à necessidade de intercambiar informação bibliográfica e de arquivos. Como vimos, seu alcance inicial foi reduzido, tanto em termos geográficos quanto ideológicos, e se limitou a alguns países da Europa Ocidental e a instituições vinculadas sobretudo ao movimento socialdemocrata. Embora lentamente, essa demarcação foi se tornando mais difusa com o passar dos anos, e instituições de diferentes origens geográficas e filiações institucionais e ideológicas aderiram à associação.

Por outro lado, ao longo das décadas, as mesmas necessidades técnicas que haviam promovido o estabelecimento de vínculos entre as instituições em 1970 foram se modificando, alterando, assim, a forma como os diferentes centros se relacionam. Hoje estamos longe do tempo em que a única forma de saber em que arquivo ou biblioteca se encontrava determinada fonte era ter uma lista dos seus materiais ou, pelo menos, ter acesso à informação necessária para se comunicar por telefone ou por correspondência com a pessoa adequada. Um dos méritos da IALHI foi adaptar-se às diferentes possibilidades técnicas que iam aparecendo e inclusive promover novos esforços colaborativos aproveitando essas oportunidades.

Nos últimos anos, a IALHI continuou crescendo e incorporando membros: mais de 25 instituições se associaram nos últimos quatro anos, e se espera um crescimento semelhante de novas afiliações em um futuro próximo. Em particular, existe o desafio de conseguir uma expansão mais sustentada nas regiões menos representadas, como a América Latina, África e Ásia, e até mesmo de promover laços e relações entre os membros dessas partes do mundo sem ter que depender de intervenção dos europeus. Este será, sem dúvida, um dos principais desafios e temas de discussão da conferência que se realizará em Buenos Aires em setembro de 2022.

Recebido em 27/05/2021

Aprovado em 05/08/2021 